\title{
Retrospective evaluation of treatment of horses with colic over a period of 15 years
}

\author{
Robin van den Boom and Marianne Sloet van Oldruitenborgh-Oosterbaan \\ Department of Equine Sciences, Faculty of Veterinary Medicine, Utrecht University
}

\begin{abstract}
Summary: Colic is a common reason for both veterinary consultation and death in horses and to help decision making in such cases recent data on the outcome of treatment and identification of prognostic indicators is important. Patient records of all horses with colic admitted to the internal medicine section of a veterinary teaching hospital (VTH) between November 2012 and October 2013 were reviewed. Age, heart rate (HR), blood lactate concentration (BLa), packed cell volume (PCV), white blood cell (WBC) count and blood pH at admission, treatment and outcome were recorded. Results were compared to those obtained at the same institution during 2006-2007 and 1999-2000. During the present study period 867 horses were admitted and 311 (36\%) of these were admitted for colic, 207/311 (67\%) of these horses were treated medically, $67 / 311$ (22\%) surgically and $37 / 311$ (12\%) were euthanized on admission. The short-term survival, defined as discharge from the hospital, for surgically treated colic cases was $60 \%$, while the survival for medically treated cases was $86 \%$. When all colic cases were analysed together HR $(P<0.01)$, blood lactate $(P<0.01), P C V(P<0.01)$ and $p H(P<0.01)$ all differed significantly between survivors and non-survivors. When only treated cases (medical and surgical) were included $H R(P<0.01)$, blood lactate $(P<0.01)$ and $p H$ $(P<0.05)$ were still significantly different. In the medically treated group only $H R(P<0.01)$ and lactate $(P<0.01)$ were significantly lower in survivors than non-survivors, while in the surgically treated group there were no differences between survivors and non-survivors. Blood lactate $(>1.5 \mathrm{mmol} / \mathrm{L})$, heart rate $(>60 \mathrm{bpm}), \mathrm{PCV}(>42 \%)$, acidosis $(\mathrm{pH}<7.35)$ and small intestinal lesions were associated with increased odds of death. The number of horses admitted to the VTH was considerably lower during 2006-2007 compared to 1999-2000, but remained more or less constant from 2006-2007 until 2012-2013, as did the percentage of colic horses. The percentage of colic cases treated surgically has decreased slightly and the percentage of horses euthanized on admission increased slightly. Increased blood lactate concentration, heart rate, PCV, acidosis and small intestinal lesions were associated with increased risk of non-survival.
\end{abstract}

Keywords: colic, horse, treatment, prognosis, retrospective

Citation: Robin van den Boom and Marianne Sloet van Oldruitenborgh-Oosterbaan (2018) Retrospective evaluation of treatment of horses with colic over a period of 15 years. Pferdeheilkunde 34, 447-453; DOI 10.21836/PEM20180506

Correspondence: Dr. Robin van den Boom, Department of Equine Sciences, Faculty of Veterinary Medicine, Utrecht University, Yalelaan 114,3584 CM, Utrecht, The Netherlands; r.vandenboom@uu.nl

\section{Introduction}

Colic is a common reason for both veterinary consultation and death in horses, and the most common reason for equine admissions to the Veterinary Teaching Hospital (VTH) at Utrecht University. Estimates on the incidence of colic range from 4.2 to 10.6 colic cases/100 horse-years in the United States and Great Britain (Kaneene et al. 1997, Tinker et al. 1997, Hillyer et al. 2001, Traub-Dargatz et al. 2001). Tinker et al. (1997) reported that $28 \%$ of all equine fatalities were the result of colic and case fatality rates for horses with colic of 6.7-18.2\% have been published (Proudman 1992, Tinker et al. 1997, Kaneene et al. 1997, Curtis et al. 2015).

Most cases of colic resolve spontaneously, or soon after medical treatment, but approximately $7-10 \%$ of cases, including certain displacements and especially strangulating lesions, are usually fatal without surgery (Proudman 1992, Thoefner et al. 2000, van der Linden et al. 2003). Curtis et al. (2015) found that of 822 colic cases presented for primary evaluation by veterinary practitioners, $23.6 \%$ could be categorised as 'critical' and required intensive medical treatment, surgical intervention, died or were euthanized, and early identification of these critical cases is crucial as any delay in diagnosis will negatively affect prognosis (Fischer 1997). In a referral hospital setting the colic cases seen are generally more severe and the probability that surgery is required is greater, than in the general population. Mortality rates of
$16.6 \%$ and $25 \%$ have been reported for colic cases treated at a referral hospital, in Germany and Israel respectively (Johnson and Keller 2005, Sutton et al. 2009). These figures are similar to what has been reported in our VTH, with a mortality rate of $31 \%$ in 2000 and $27 \%$ in 2007 (van der Linden et al. 2003, Sloet van Oldruitenborgh-Oosterbaan 2008).

In a (teaching) hospital or referral clinic, horses requiring surgery need to be identified and when deciding on the most appropriate treatment both owners and veterinarians wish to have an estimate of the prognosis for survival. Accurate and recent data regarding the outcome of colic cases are essential for clinical decision making (Mair et al. 2007). Further, it can be useful to compare results to those obtained previously, both in the same hospital and elsewhere, as differences may provide clues as to how the management of colic cases can be improved in the future, and Mair and White (2005) suggested an international audit was indicated for the improvement of quality of care in colic surgery.

In addition to knowing the results from the past, it is valuable to know whether clinical and/or biochemical parameters reflect survival in colic cases. Many studies have been performed to identify prognostic indicators in colic horses and although it is unlikely that a single factor can be found that will accurately predict survival in all cases, various parameters have been linked to prognosis in equine colic and it can help to know which factors play a role in a particular hospital. 
The objectives of the present study were to establish short-term survival rates for medically and surgically treated colic cases in our VTH and to compare these to data obtained previously. In addition, we aimed to identify potential prognostic indicators in colic horses referred to a university teaching hospital.

\section{Materials and methods}

The patient records of all colic horses admitted to the internal medicine section of the Department of Equine Sciences at Utrecht University between November 1st 2012 and October 31 st 2013 (period A) were reviewed. Colic was defined as any incidence of abdominal pain as assessed by the attending veterinary surgeon. Heart rate (HR), blood lactate concentration (BLa), packed cell volume (PCV), white blood cell (WBC) count and blood $\mathrm{pH}$ at admission, treatment (none, medical or surgical), site of lesion (stomach, small intestine or large intestine) and short-term survival (survival to discharge) were recorded. The number of colic cases was compared to the total number of horses admitted to the hospital and the per- centage of horses treated medically and surgically, or euthanized, was calculated. The decision to euthanize a horse was usually based on a combination of the estimated prognosis and/or estimated treatment costs. For each treatment category, statistical analysis was performed to determine whether there was a significant difference between survivors and non-survivors in age, heart rate or biochemical parameters. Results for period $A$ were then compared to those obtained at our VTH during 2006-2007 (period B, Sloet van OldruitenborghOosterbaan 2008) and to those obtained between 1999 and 2000 (period C, van der Linden et al. 2003).

Statistical analysis was performed using SPSS software (IBM version 24) and the level of significance was set at $\mathrm{P}<0.05$. Data (HR, blood lactate, $\mathrm{pH}, \mathrm{PCV}$ and WBC count) were analysed for normality using a Kolmogorov-Smirnov and Shapiro Wilk test, before and after log transformation and only log PCV was normally distributed. Therefore, a Mann-Whitney U test was used to assess differences between outcomes (survival and non-survival) for HR, BLa, pH, WBC count and lesion location (small or large intestine) and a student's t-test was

Table 1 The number of colic cases and total number of cases admitted during periods A, B and C, the type of treatment and the short-term outcome per treatment category. Different superscripts denote statistically significant differences between groups.

\begin{tabular}{|c|c|c|c|}
\hline & Period A & Period B & Period C \\
\hline & $2012-2013$ & $2006-2007$ & $1999-2000$ \\
\hline Total cases admitted & $n=867$ & $\mathrm{n}=885$ & $n=1837$ \\
\hline Gastrointestinal colic & $311=36 \%$ & $350=40 \%$ & $649=35 \%$ \\
\hline Surgical treatment & $67=22 \%^{a}$ & $112=32 \%^{b}$ & $183=28 \%^{b}$ \\
\hline Medical treatment & $207=67 \%$ & $202=58 \%$ & $412=64 \%$ \\
\hline No treatment & $37=12 \%$ & $36=10 \%$ & $54=8 \%$ \\
\hline Total survivors & $218=70 \%$ & $254=73 \%$ & $450=69 \%$ \\
\hline Survivors treated & $218=80 \%$ & $254=81 \%$ & $450=76 \%$ \\
\hline Surgery - survivors & $40=60 \%$ & $61=54 \%$ & $98=54 \%$ \\
\hline Medical - survivors & $178=86 \%^{a}$ & $193=96 \%{ }^{b}$ & $352=85 \%^{a}$ \\
\hline
\end{tabular}

Table 2 Heart rate (HR), plasma lactate concentration, packed cell volume (PCV), white blood cell count (WBC) and pH of the horses admitted with colic during periods $A$ and $B$. Mean \pm standard deviation. ${ }^{*}=$ significant difference $(p<0.01)$ between survivors and non-survivors within a category and ${ }^{\S}=$ significant difference $(p<0.05)$ compared to horses that were not treated and $\S^{\S}=$ significant difference $(p<0.01)$ compared to horses that were not treated.

\begin{tabular}{|c|c|c|c|c|c|c|c|}
\hline & Category & & $\mathrm{HR}(\mathrm{bpm})$ & Lactate $(\mathrm{mmol} / \mathrm{l})$ & PCV (\%) & $\operatorname{WBC}\left(10^{9} / \mathrm{I}\right)$ & $\mathrm{pH}$ \\
\hline \multirow{9}{*}{ 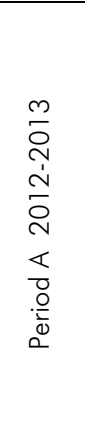 } & \multirow{3}{*}{ All cases } & Survivors & $46 \pm 14^{\S \S}$ & $1.4 \pm 1.2^{\S \S}$ & $33 \pm 5^{\S \S}$ & $8.6 \pm 2.8$ & $7.42 \pm 0.03^{\S}$ \\
\hline & & Treated non-surv & $58 \pm 22^{\S}$ & $2.4 \pm 2.3^{\S \S}$ & $35 \pm 10^{\S \S}$ & $8.3 \pm 3.2$ & $7.40 \pm 0.06$ \\
\hline & & Non-survivors all & $63 \pm 25^{*}$ & $2.9 \pm 2.4^{*}$ & $38 \pm 11^{*}$ & $8.4 \pm 3.9$ & $7.40 \pm 0.06^{*}$ \\
\hline & \multirow{2}{*}{ Surgery } & Survivors & $51 \pm 13^{\S}$ & $2.1 \pm 2.3^{\S}$ & $35 \pm 4^{\S}$ & $8.6 \pm 3.2$ & $7.40 \pm 0.03$ \\
\hline & & Non-survivors & $59 \pm 21$ & $2.5 \pm 1.9$ & $36 \pm 9 \S$ & $8.5 \pm 2.7$ & $7.39 \pm 0.06$ \\
\hline & \multirow{2}{*}{ Medical } & Survivors & $44 \pm 14^{\S}$ & $1.2 \pm 0.7^{\S}$ & $33 \pm 5^{\S}$ & $8.6 \pm 2.7$ & $7.42 \pm 0.03^{\S}$ \\
\hline & & Non-survivors & $58 \pm 22 * \S$ & $2.3 \pm 2.6^{* \S \S}$ & $36 \pm 8^{\S}$ & $8.2 \pm 3.6$ & $7.40 \pm 0.05$ \\
\hline & \multirow{2}{*}{ Treatment } & Treated & $48 \pm 17^{\S \S}$ & $1.6 \pm 1.6^{\S \S}$ & $34 \pm 6^{\S \S}$ & $8.6 \pm 2.9$ & $7.42 \pm 0.04$ \\
\hline & & No treatment & $71 \pm 27$ & $3.6 \pm 2.5$ & $43 \pm 11$ & $8.5 \pm 4.8$ & $7.39 \pm 0.06$ \\
\hline \multirow{5}{*}{ 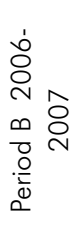 } & \multicolumn{2}{|c|}{ Surgery - survivors } & $56 \pm 20$ & $2.4 \pm 2.3$ & $38 \pm 7$ & $8.9 \pm 2.7$ & $7.38 \pm 0.06$ \\
\hline & \multicolumn{2}{|c|}{ Surgery - non-survivors } & $65 \pm 22$ & $4.0 \pm 3.1^{*}$ & $41 \pm 9$ & $9.0 \pm 3.5$ & $7.38 \pm 0.05$ \\
\hline & \multicolumn{2}{|c|}{ Medical - survivors } & $47 \pm 13$ & $1.4 \pm 1.0$ & $36 \pm 7$ & $8.5 \pm 2.8$ & $7.40 \pm 0.04$ \\
\hline & \multicolumn{2}{|c|}{ Medical - non-survivors } & $64 \pm 27$ & $5.2 \pm 7.0^{*}$ & $52 \pm 9$ & $7.7 \pm 6.8$ & $7.35 \pm 0.08$ \\
\hline & \multicolumn{2}{|l|}{ No treatment } & $72 \pm 28$ & $6.3 \pm 5.6$ & $44 \pm 10$ & $8.2 \pm 4.4$ & $7.35 \pm 0.07$ \\
\hline
\end{tabular}


used to assess differences in PCV. To compare results between periods a chi-squared test was used. The association between variables (HR, BLa, pH, PCV and WBC count) and outcome was analysed initially with logistic regression in a univariate fashion. Variables screened in univariate and retained with $\mathrm{P}<0.15$ were assessed via multivariate analysis using forward stepwise logistic regression.

\section{Results}

Number of cases

Sixty-seven per cent $(207 / 311)$ of the colic cases were treated medically, 22\% (67/311) surgically and 12\% (37/311) were euthanized without treatment (table 1).

\section{Survival}

The number of colic cases, the total number of cases, the percentage of colic cases, the percentage of medically and surgically treated colic cases and the short-term survival (survival to discharge) are shown in table 1 for periods $A, B$ and $C$.

Overall, survival for medical cases was significantly higher than for surgical cases. When comparing the different study periods there was no difference in total survival (all colic cases) or survival of surgical cases, but the percentage of medically treated horses that survived was higher in period B (2006-2007) compared to periods $A$ and $C$ and more horses were treated surgically in periods $B(2006-2007)$ and $C$ (1999-2000) compared to the present study period.

\begin{tabular}{|c|c|c|c|c|c|c|c|c|c|c|c|c|c|}
\hline \multirow[b]{4}{*}{ lactate } & \multirow{2}{*}{\multicolumn{5}{|c|}{ all cases }} & \multirow{2}{*}{\multicolumn{4}{|c|}{ surgical }} & \multirow{2}{*}{\multicolumn{4}{|c|}{ medical }} \\
\hline & & & & & & & & & & & & & \\
\hline & & \multirow{2}{*}{$\begin{array}{r}\begin{array}{r}\text { OR - } \\
\text { death }\end{array} \\
1.0\end{array}$} & \multirow[t]{2}{*}{$\mathrm{p}$} & \multicolumn{2}{|c|}{$95 \% \mathrm{Cl}$} & \multirow[t]{2}{*}{$\begin{array}{l}\text { OR - } \\
\text { death }\end{array}$} & \multirow[t]{2}{*}{$\mathrm{p}$} & \multicolumn{2}{|c|}{$95 \% \mathrm{Cl}$} & \multirow[t]{2}{*}{$\begin{array}{l}\text { OR - } \\
\text { death }\end{array}$} & \multirow[t]{2}{*}{$\mathrm{p}$} & \multicolumn{2}{|c|}{$95 \% \mathrm{Cl}$} \\
\hline & $<2$ & & & & & & & & & & & & \\
\hline & $>1$ & 4.36 & 0.000 & 2.41 & 7.91 & 2.19 & 0.13 & 0.72 & 6.66 & 2.98 & 0.009 & 1.25 & 7.14 \\
\hline & $>1.5$ & 5.30 & 0.000 & 3.09 & 9.08 & 2.09 & 0.114 & 0.771 & 5.67 & 3.53 & 0.004 & 1.51 & 8.21 \\
\hline & $>2$ & 5.11 & 0.000 & 2.88 & 9.05 & 2.36 & 0.082 & 0.85 & 6.61 & 2.67 & 0.050 & 1.00 & 7.10 \\
\hline & $>3$ & 7.58 & 0.000 & 3.70 & 15.52 & 1.94 & 0.188 & 0.64 & 5.91 & 5.53 & 0.024 & 1.39 & 22.05 \\
\hline & $>4$ & 10.82 & 0.000 & 4.19 & 27.94 & 3.06 & 0.090 & 0.80 & 11.76 & 10.14 & 0.021 & 1.61 & 63.71 \\
\hline & $>6$ & 13.51 & 0.000 & 2.89 & 63.04 & 1.48 & 0.544 & 0.20 & 11.21 & & 0.019 & & \\
\hline \multirow[t]{4}{*}{$H R$} & $<44$ & 1.0 & & & & & & & & & & & \\
\hline & $>44$ & 5.74 & 0.000 & 3.30 & 10.00 & 1.46 & 0.322 & 0.52 & 4.07 & 4.61 & 0.000 & 1.99 & 10.71 \\
\hline & $>40$ & 3.39 & 0.000 & 1.92 & 5.97 & 0.88 & 0.519 & 0.30 & 2.62 & 2.52 & 0.023 & 1.08 & 5.88 \\
\hline & $>60$ & 8.46 & 0.000 & 4.42 & 16.20 & 2.42 & 0.097 & .80 & 7.34 & 6.00 & 0.002 & 2.02 & 17.80 \\
\hline \multirow[t]{2}{*}{$\mathrm{H} \dagger$} & $<42$ & 1.0 & & & & & & & & & & & \\
\hline & $>42$ & 15.60 & 0.000 & 6.16 & 39.54 & 9.25 & 0.032 & 1.01 & 84.73 & 10.88 & 0.000 & 3.18 & 37.25 \\
\hline \multirow[t]{3}{*}{ WBC } & $<12$ & 1.0 & & & & & & & & & & & \\
\hline & $>12$ & 1.88 & 0.079 & 0.88 & 4.02 & 1.06 & 0.649 & 0.164 & 6.86 & 1.23 & 0.487 & 0.33 & 4.55 \\
\hline & $<4$ & 4.85 & 0.001 & 1.96 & 12.03 & 1.64 & 0.505 & 0.22 & 12.47 & 3.25 & 0.120 & 0.77 & 13.80 \\
\hline \multirow[t]{2}{*}{$\mathrm{pH}$} & $<7.35$ & 6.76 & 0.000 & 2.67 & 17.12 & 2.92 & 0.153 & 0.63 & 13.51 & 9.02 & 0.003 & 2.26 & 36.05 \\
\hline & $>7.45$ & 0.80 & 0.329 & 0.39 & 1.62 & 3.22 & 0.345 & 0.276 & 37.52 & 0.839 & 0.483 & 0.30 & 2.36 \\
\hline \multirow[t]{2}{*}{ location } & $\mathrm{LI}$ & & & & & & & & & & & & \\
\hline & $\mathrm{SI}$ & 5.96 & 0.000 & 3.37 & 10.53 & 3.45 & 0.018 & 1.20 & 9.93 & 4.61 & 0.002 & 1.80 & 11.77 \\
\hline
\end{tabular}

\begin{tabular}{|c|c|c|c|c|c|c|c|c|c|c|c|c|c|}
\hline \multirow{3}{*}{ lactate } & \multicolumn{5}{|c|}{ all cases } & \multicolumn{4}{|c|}{ surgical } & \multicolumn{4}{|c|}{ medical } \\
\hline & & $\begin{array}{l}\text { OR - } \\
\text { death }\end{array}$ & $p$ & \multicolumn{2}{|c|}{$95 \% \mathrm{Cl}$} & $\begin{array}{l}\text { OR - } \\
\text { death }\end{array}$ & $p$ & \multicolumn{2}{|c|}{$95 \% \mathrm{Cl}$} & $\begin{array}{l}\text { OR - } \\
\text { death }\end{array}$ & $p$ & \multicolumn{2}{|c|}{$95 \% \mathrm{Cl}$} \\
\hline & $<1.3$ & 1.00 & & & & & & & & & & & \\
\hline & $>1.5$ & 5.30 & 0.000 & 3.09 & 9.08 & & & & & 3.53 & 0.004 & 1.51 & 8.21 \\
\hline \multirow[t]{2}{*}{$H R$} & $<44$ & 1.00 & & & & & & & & & & & \\
\hline & $>44$ & 5.74 & 0.000 & 3.30 & 10.00 & & & & & & & & \\
\hline \multirow[t]{2}{*}{$\mathrm{Ht}$} & $<42$ & 1.00 & & & & & & & & & & & \\
\hline & $>42$ & 15.60 & 0.000 & 6.16 & 39.54 & 9.25 & 0.032 & 1.01 & 84.73 & 10.88 & 0.000 & 3.18 & 37.25 \\
\hline $\mathrm{pH}$ & $<7.35$ & 6.76 & 0.000 & 2.67 & 17.12 & & & & & & & & \\
\hline \multirow[t]{2}{*}{ location } & LI & & & & & & & & & & & & \\
\hline & SI & 5.96 & 0.000 & 3.37 & 10.53 & 3.45 & 0.018 & 1.20 & 9.93 & 4.61 & 0.002 & 1.80 & 11.77 \\
\hline
\end{tabular}




\section{Prognostic indicators}

When all colic cases admitted (including those that were euthanized on admission) were analysed together HR $(P<0.01, n=299)$, BLa $(P<0.01, n=297)$, $P C V(P<0.01$, $\mathrm{n}=301)$ and $\mathrm{pH}(\mathrm{P}<0.01, \mathrm{n}=292)$ all differed significantly between survivors and non-survivors, whereas WBC count $(P=0.876, n=301)$ did not (table 2$)$. When only treated cases (medical and surgical) were included $H R(P<0.01)$, BLa $(P<0.01)$ and $\mathrm{pH}(\mathrm{P}<0.05)$ were still significantly different but $P C V(P=0.081)$ and $W B C$ count $(P=0.646)$ were not. In the medically treated group only $H R(P<0.01)$ and blood lactate $(P<0.01)$ were significantly lower in survivors than non-survivors, while in the surgically treated group there were no differences between survivors and non-survivors.

In the final model blood lactate $(>1.5 \mathrm{mmol} / \mathrm{L})$, heart rate (>60 bpm), PCV (>42\%), acidosis $(\mathrm{pH}<7.35)$ and small intestinal lesion were associated with increased odds of death, when all cases were considered. For medically treated colic cases the odds of death were increased with increased blood lactate concentration, PCV and small intestinal lesions and in the surgically treated group only for increased PCV and small intestine location (tables 3 and 4).

\section{Discussion}

The total number of horses admitted to our hospital has fallen considerably since 1999-2000 but remained more or less constant between 2007 and 2013, while the percentage of colic horses has remained equal. The decrease in horses presenting could be a result of an increased number of equine clinics in the Netherlands in which colic surgery can be performed. In colic cases requiring surgery the prognosis for survival depends on early referral (Cook and Hassel 2014), and referring vets are likely to send horses with colic to the closest available clinic where surgery is possible. It is also possible that horses were not being referred because owners were unable, or not prepared, to pay the additional costs associated with referral and further treatment, including the possibility of surgery.

The percentage of colic cases treated surgically was approximately $30 \%$ in the first two periods and was $22 \%$ in the present study, significantly less than before. However, this figure is very similar to the $21 \%$ of horses with colic undergoing surgery reported by Christophersen et al. (2014) in Denmark. In contrast, the number of horses euthanized on admission, increased slightly in each study period, although the difference was not statistically significant. Both effects were also reported by Blikslager and Mair (2014) and could be a result of the global financial crisis, the results of which became evident after 2008. This is difficult to prove as many factors influence the decision on whether or not to terminate treatment, but Wormstrand et al. (2014) and Blikslager and Mair (2014) also speculated that economic reasons may have played a role in the decision to euthanize horses presenting with colic. A number of recent publications have suggested that attitudes towards animal welfare and euthanasia may vary and should also be taken into consideration when comparing the results of colic treatment (Sutton et al. 2009, Wormstrand et al. 2014). However, this is not likely to have influenced the results of the present study, as it seems unlikely that these attitudes will have changed significantly since 1999 in the Netherlands. The average heart rate, blood lactate concentration and PCV were all significantly higher in horses euthanized on admission compared to both medical and surgical non-survivors, suggesting that some of those horses did indeed have a poor prognosis. However, for other horses that were euthanized on admission the decision to euthanize was based mainly on financial constraints.

The overall short-term survival did not differ significantly for the three study periods and is similar to the $75 \%$ reported by Sutton et al. (2009). Also, the short-term survival of medically treated colic cases in the present study (86\%) was not significantly different when compared to period $C$ and almost exactly the same as the $87 \%$ reported by Christopherson et al. (2014) in Denmark, and slightly lower than the $93 \%$ reported by Johnson and Keller (2005) in Germany and Sutton et al. (2009) in Israel. However, the results for period B were significantly better. The short-term survival of surgical cases was similar to results published previously, including two recent publications from Northern Europe (Christophersen et al. 2014, Wormstrand et al. 2014), but higher than the $35 \%$ reported by Elbert (1994) for horses undergoing colic surgery during the 1980's. This would suggest that the results of colic surgery have improved over the last 30 years, but that is not necessarily the case as Puotunen-Reinert and Huskamp (1985) reported that 76/105 (72\%) surgical colic cases survived between November 1982 and June 1983.

In the present study PCV was significantly higher in non-survivors than in survivors, and had the highest odds ratio for death, which is in accordance with findings by Puotunen-Reinert and Huskamp (1985), Proudman et al. (2006) and Krueger et al. (2014) who reported that both intra- and post-operative mortality were positively correlated with $\mathrm{PCV}$. The increased PCV probably reflects more severe hypovolemia and cardiovascular compromise.

The risk of non-survival was greater for small intestinal lesions than for those affecting the large intestine, for both surgically and medically treated horses. This is in accordance with the findings of Wormstrand et al. (2014), van der Linden et al. (2003), Mair and Smith (EVJ 2005) and Proudman (1992), and probably related to the fact that strangulating lesions are more common in the small intestine and surgical lesions have a poorer prognosis than those that can be managed medically.

The medically managed horses were cases that had a diagnosis that would normally be expected to resolve with supportive management, without surgery, or those in which surgery was advised but declined by the owner. The reason not to opt for surgery was usually based on the estimated costs, often in combination with the estimated prognosis. Other factors that sometimes played a role in an owner's decision were the age of the horse, a prior poor experience with a horse undergoing colic surgery, the fear of complications or concurrent illness or injury. In many cases the exact reason was not specified by the owner.

In medically treated colic cases the blood lactate concentration was significantly lower in horses that were discharged from the hospital (survivors) than in those that were not (nonsurvivors), while the difference was not significant in the sur- 
gically treated group. This may have been due to limited statistical power as Puotunen-Reinert and Huskamp (1985) found that blood lactate concentrations were significantly higher in horses that died after colic surgery than in those that survived. Although an elevated blood lactate concentration is usually associated with ischemic intestine (Cook and Hassel 2014), and therefore may indicate the need for surgery, it is not always correlated with the outcome in individual cases. Furr et al. (1995) also found that some horses with a very high blood lactate concentration survived and blood lactate alone was not a good predictor of outcome. The higher blood lactate concentration in medical non-survivors is in accordance with findings during period $B$ and those reported by Moore et al. (1976), Orsini et al. (1988) and Delesalle et al. (2007). In 2013 Dunkel et al. reported that ponies with gastrointestinal disease presented with higher blood lactate concentrations than horses. The difference in blood lactate concentrations between horses and ponies was not examined in the present study as only a small percentage of cases $(<10 \%)$ were ponies.

Several studies, including those by Latson et al. (2005), Delesalle et al. (2007) and van den Boom et al. (2010) have been published demonstrating that the lactate concentration in peritoneal fluid can also help to predict the need for surgery and survival in horses with colic. More recently, Peloso and Cohen (2012) demonstrated the value of serial measurements of peritoneal fluid lactate concentrations in predicting the presence of a strangulating intestinal lesion in horses with colic. Peritoneal lactate concentrations were not routinely measured in the present study period, while in some cases serial blood lactate measurements were used to guide decision making, as lactate is considered to diffuse rapidly to the bloodstream.

During period A (2012-2013) of the present study the heart rate was significantly higher in medically treated non-survivors than survivors, while the difference was not significant in the surgically treated group, although this may have been due to a lack of statistical power. During period B (2006-2007), the heart rate did not differ between survivors and non-survivors. Finally, in period C (1999-2000), heart rate was also found to be useful as a prognostic indicator. Heart rate has previously been identified as a factor in differentiating critical from non-critical colic cases (Jennings et al. 2014, Curtis et al. 2015) and has been found to predict mortality in colic cases (Puotunen-Reinert and Huskamp 1985, Orsini et al. 1988, Reeves et al. 1989, Furr et al. 1995). McConachie et al. (2016) also published that post-operative $\mathrm{HR}$ was higher in horses with ischaemic gastrointestinal disease than in those with non-ischaemic gastrointestinal lesions. It is likely that heart rate, as PCV, reflects cardiovascular compromise in colic cases. In addition to the data regarding heart rate, McConachie et al. (2016) also found that heart rate variability (HRV) may be of prognostic significance, with reduced HRV being associated with non-survival.

There was a statistically significant difference in blood $\mathrm{pH}$ between survivors and non-survivors, and acidosis was associated with increased odds of death, although it is unclear whether this difference is clinically relevant, as mean values for both groups were within the reference range. The higher blood lactate concentration in non-survivors would likely explain the lower $\mathrm{pH}$ in that group of horses, although impaired ventilation due to distended abdominal contents may also contribute, through an increase in $\mathrm{PaCO}_{2}$.

No significant differences in white blood cell counts were identified between survivors and non-survivors in any of the study periods, although leukopenia was included in the initial univariate analysis, but not in the final model of the present study. A study by Pih/ et al (2015) demonstrated that the WBC count could not be used to distinguish inflammatory diseases from strangulating obstructions in horses with colic. The WBC count would be expected to be extremely low in cases of acute peritonitis from intestinal rupture or endotoxaemia and potentially elevated in cases of proximal enteritis or intraabdominal abscesses, but generally within reference range in most horses with colic (Mair 2002).

The main limitations of the present study are the retrospective nature and the fact that results only apply to our VTH, although similarities to other referral centres are likely to exist. The fact that this was a retrospective study meant that the reasons for euthanasia could not be determined and also that it was not possible to collect additional data that had not been recorded at the time of admission.

In conclusion, surgery was performed on approximately one quarter of the horses admitted to our hospital because of colic. Just over half of those surgical cases survived until hospital discharge, compared to over $85 \%$ of medically treated cases and $70 \%$ of all colic cases. In our hospital, elevated PCV, small intestinal lesions, increased blood lactate concentration, elevated heart rate and the presence of acidosis were associated with increased risk of death.

\section{References}

Blikslager A. T., Mair T. S (2014) Trends in management of horses referred for evaluation of colic: 2004-2013. In: Proceedings of the 11 th Equine Colic Research Symposium, Dublin, Ireland.

Christopherson M. T., Dupont N., Berg-Sorenson K. S., Konnerup C., Pihl T. H., Anderson P. H. (2014) Short-term survival and mortality rates in a retrospective study of colic in 1588 Danish horses. Acta Vet. Scand. 56, 20; DOI 10.1186/1751-0147-56-20

Cook V. L., Hassel D. M. (2015) Evaluation of the Colic in Horses: Decision for Referral. Vet. Clin. North Am. Equine Pract. 30, 383398; DOI 10.1016/i.cveq.2014.04.001

Curtis L., Burford J. H., Thomas J. S. M., Curran M. L., Bayes T. C., England G. C. W., Freeman S. L. (2015) Prospective study of the primary evaluation of 1016 horses with clinical signs of abdominal pain by veterinary practicioners, and the differentiation of critical and non-critical cases. Acta Vet. Scand. 57, 69; DOI 10.1186/s13028-015-0160-9

Delesalle C., Dewulf J., Lefebvre R. A., Schuurkes J. A. J., Proot J., Lefere L., Deprez P. (2007) Determination of lactate concentrations in blood plasma and peritoneal fluid in horses with colic by an Accusport analyzer. J. Vet. Int. Med. 21, 293-301; DOI 10.1111/i.1939-1676.2007.tb02963.x

Dunkel B., Kapff J. E., Naylor R. J., Boston R. (2013) Blood lactate concentrations in ponies and miniature horses with gastrointestinal disease. Equine Vet. J. 45, 666-670; DOi 10.1111/evj.12043

Elbert R. (1994) Letalitätsaspekte der Kolik des Pferdes. Pferdeheilkunde 10,97-101; DOI 10.21836/PEM19940204

Fischer A. T. (1997) Advances in diagnostic techniques for horses with colic. Vet. Clin. North Am. Equine Pract. 13, 203-219; DOI 10.1016/S0749-0739(17)30237-7 
Furr M. O., Lessard P., White N. A. 2nd. (1995) Development of a colic severity score for predicting the outcome of equine colic. Vet. Surg. 24, 97-101; DOi 10.1111/j.1532-950X.1995.tb01302.x

Hillyer M. H., Taylor F. G. R., French N. P. (2001) A cross-sectional study of colic in horses on Thoroughbred training premises in the British Isles in 1997. Equine Vet. J. 33, 380-385; DOI 10.2746/042516401776249499

Jennings K. M., Curtis L., Burford J. H., Freeman S. L. (2014) Prospective survey of veterinary practitioners' primary assessment of equine colic: clinical features, diagnoses, and treatment of 120 cases of large colon impaction. BMC Vet. Res. 10 (Suppl 1), S2; DOI 10.1186/1746-6148-10-S1-S2

Johnson A., Keller H. (2005) Ergebnisse von 1.431 stationär behandelten Kolikpatienten, unter besonderer Berücksichtigung der 285 chirurgisch versorgten Pferde, in den Jahren 1990 bis 1997 in der Klinik für Pferde, Allgemeine Chirurgie und Radiologie der Freien Universität Berlin. Pferdeheilkunde 25, 427-438; DOI 10.21836/PEM20050506

Kaneene J. N., Ross W. A., Miller R. (1997) The Michigan equine monitoring system. II. Frequencies and impact of selected health problems. Prev. Vet. Med. 29, 277-292; DOPi 10.1016/S0167. 5877(96)01080-X

Krueger C. R., Ruple-Czerniak A., Hacket E. S. (2014) Evaluation of plasma muscle enzyme activity as an indicator of lesion characteristics and prognosis in horses undergoing celiotomy for acute gastrointestinal pain. BMC Vet. Res. 10 (Suppl 1), S7; DOI 10.1186/1746-6148-10-S1-S7

Latson K. M., Nieto J. E., Beldomenico P. M., Snyder J. R. (2005) Evaluation of peritoneal fluid lactate as a marker of intestinal ischaemia in equine colic. Equine Vet. J. 37, 342-346; DOi 10.2746/0425164054529319

Mair T. S. (2002) Clinical evaluation of the colic case. In: Manual of Equine Gastroenterology, Eds: Mair T.S., Divers T., Ducharme N. WB Saunders, Edinburgh, pp: 107-144.

Mair T. S., Smith L. J. (2005) Survival and complication rates in 300 horses undergoing surgical treatment of colic. Part 1: short-term survival following a single laparotomy. Equine Vt. J. 37, 296-302; DOI 10.2746/0425164054529409

Mair T. S., White N. A. (2005) Improving quality of care in colic surgery: time for international audit? Equine Vet. J. 37, 287-288; DOi 10.2746/0425164054529490

Mair T. S., Smith L. J., Sherlock C. E. (2007) Evidence-based gastrointestinal surgery in horses. Vet. Clin. Equine Pract. 23, 267-292; DOI 10.1016/i.cveq.2007.03.005

McConachie E. L., Giguere S., Rapoport G., Barton M. H. (2016) Heart rate variability in horses with acute gastrointestinal disease requiring exploratory laparotomy. J. Vet. Emerg. Crit. Care 26, 269-280; DOI 10.1111/vec.12362

Moore J. N., Owen R. R., Lumsden J. H. (1976) Clinical evaluation of blood lactate levels in equine colic. Equine Vet. J. 8, 49-54; DOi 10.1111/j.2042-3306.1976.tb03289.x

Orsini J. A., Elser A. H., Galligan D. T., Donawick W. J., Kronfeld D. S. (1988) Prognostic index for acute abdominal crisis (colic) in horses. Am. J. Vet. Res. 49, 1969-1971

Peloso J. G., Cohen N. D. (2012) Use of serial measurements of peritoneal fluid lactate concentration to identify strangulating intestinal lesions in referred horses with signs of colic. J. Am. Vet. Med. Assoc. 240, 1208-1217; DOi 10.2460/javma.240.10.1208

Proudman C. J. (1992) A two year, prospective survey of equine colic in general practice. Equine Vet. J. 24,90-93; DOI 10.1111/j. 2042-3306.1992.tb02789.x

Proudman C. J., Dugdale A. H., Senior J. M., Edwards G. B., Smith J. E., Leuwer M. L., French N. P. (2006) Pre-operative and anaesthesia-related risk factors for mortality in equine colic cases. Vet. J. 17,89-97; DOi 10.21836/PEM19850301

Puotunen-Reinert A., Huskamp B. (1985) Möglichkeiten der Prognostik beim chirurgischen Kolikpferd: Untersuchung von 110 Fällen. Pferdeheilkunde 1, 123-129; DOI 10.21836/PEM1985 0301

Reeves M. J., Curtis C. R., Salman M. D., Hilbert B. J. (1989) Prognosis in equine colic patients using multivariable analysis. Can. J. Vet. Res. 53, 87-94
Sloet van Oldruitenborgh-Oosterbaan M. M. (2008) Blood-lactate concentration and prognosis in equine gastro-intestinal colic. In: Proceedings International Veterinary Congress Voorjaarsdagen, Amsterdam, NL, p.328

Sutton G. A., Ertzman-Ginsburg R., Steinman A., Milgram J. (2009) Initial investigation of mortality rates and prognostic indicators in horses with colic in Israel: a retrospective study. Equine Vet. J. 41, 482-486; DOi 10.2746/042516409X391060

Thoefner M. B., Ersbell A. K., Hesselholt M. (2000) Prognostic indicators in a Danish hospital-based population of colic horses. Equine Vet. J. 32 (S32), 11 -18; DOI 10.1111/j.2042-3306.2000.tb 05328.x

Tinker M. K., White N. A., Lessard P., Thatcher C. D., Pelzer K. D., Davis, B., Carmal, D. K. (1997) Prospective study of equine colic incidence and mortality. Equine Vet. J. 29, 448-453; DOi 10.1111/j.2042-3306.1997.tb03157.x

Traub-Dargatz J. L., Kopral C. A., Seitzinger A. H., Forde K., White N. A. (2001) Estimate of the national incidence of and operationlevel risk factors for colic among horses in the United States, spring 1998 to spring 1999. J. Am. Vet. Med. Assoc. 219, 67-71; DOI 10.2460/javma.2001.219.67

van den Boom R., Butler C. M., Sloet van Oldruitenborgh-Oosterbaan M. M. (2010) The usability of peritoneal lactate concentration as a prognostic marker in horses with severe colic admitted to a veterinary teaching hospital. Equine Vet. Ed. 22, 420-425; DOi 10.1111/i.2042-3292.2010.00093.x

van der Linden M. A., Laffont C. M., Sloet van OldruitenborghOosterbaan M. M. (2003) Prognosis in Equine Medical and Surgical Colic. J. Vet. Int. Med. 17, 343-348; DOI 10.1111/i.19391676.2003.tb02459.x

Wormstrand B. H., Ihler C. F., Diesen R., Krontveit R. I. (2014) Surgical treatment of equine colic - a retrospective study of 297 surgeries in Norway 2005-2011 Acta Vet. Scand. 56, 38; DOI $10.1186 / 1751-0147-56-38$ 